\title{
STEP File Analyzer Software
}

\section{Robert Lipman}

National Institute of Standards and Technology, Gaithersburg, MD 20899, USA

robert.lipman@nist.gov

Software DOI: https://doi.org/10.18434/M39886

Software Version: 1.94

Key words: conformance; interoperability; manufacturing; STEP.

Accepted: March 1, 2017

Published: March 30, 2017

https://doi.org/10.6028/jres.122.016

\section{Summary}

The STEP File Analyzer is a software tool that generates a spreadsheet or a set of CSV (commaseparated value) files from a STEP (ISO 10303 -STandard for Exchange of Product model data) [1] Part 21 file [2]. STEP files are used to represent product and manufacturing information (PMI) and for data exchange and interoperability between Computer-Aided Design (CAD), Manufacturing (CAM), Analysis (CAE), and Inspection (CMM) software related to the smart manufacturing digital thread. STEP is also used for the long-term archiving and retrieval of product data [3, 4].

A spreadsheet simplifies inspecting information from the STEP file at an entity and attribute level. Typical STEP file viewers show a 3D visualization of the part or model represented by the STEP file. The viewers usually have a high-level hierarchical display of the information in the STEP file where the user can drill down to individual attributes of parts. However, there is no way to view all of the actual STEP entities and their attributes at once. The STEP File Analyzer provides this capability by creating a spreadsheet from the STEP file.

The STEP File Analyzer also generates reports for PMI Representation, PMI Presentation, and Validation Properties based on Recommended Practices defined by the CAx Implementor Forum_(CAx-IF) [5]. The objective of the CAx-IF is to advance CAx (mainly Computer-Aided Design and Engineering) software system STEP translator development and to ensure that user requirements for interoperability are satisfied.

\section{Software Specifications}

\begin{tabular}{ll}
\hline NIST Operating Unit(s) & $\begin{array}{l}\text { Engineering Laboratory, Systems Integration Division, Systems } \\
\text { Engineering Group }\end{array}$ \\
\hline Category & Analysis \\
\hline Targeted Users & Software developers and end-users of STEP files in CAD software \\
\hline Operating System(s) & Windows \\
\hline Programming Language & Tcl \\
\hline Inputs/Outputs & $\begin{array}{l}\text { Inputs: ISO 10303 Part 21 STEP file. Outputs: Microsoft Excel } \\
\text { spreadsheet, CSV files }\end{array}$ \\
\hline
\end{tabular}




\begin{tabular}{|c|c|}
\hline Documentation & $\begin{array}{l}\text { User’s Guide - https://www.nist.gov/node/795641 } \\
\text { Source Code - https://github.com/usnistgov/SFA } \\
\text { Webpage - https://www.nist.gov/services-resources/software/step- } \\
\text { file-analyzer }\end{array}$ \\
\hline Accessibility & N/A \\
\hline Disclaimer & https://www.nist.gov/director/licensing \\
\hline
\end{tabular}

\section{Methods}

This software provides an executable file with graphical user interface, a command-line program, and source code for a user to modify and build their own version. The software uses the IFCsvr toolkit [6] to read STEP files and STEPtools to define STEP schemas [7]. The software has been tested with thousands of STEP files and is used by the CAx-IF to perform semantic analysis of STEP AP242 [8-10] files with PMI $[11,12]$. The testing of STEP files in the CAx-IF is used to provide feedback to software vendors about their STEP implementations in CAD software.

\section{References}

[1] International Organization for Standardization (1994) ISO 10303-1:1994 - Industrial automation systems and integration Product data representation and exchange - Part 1: Overview and fundamental principles (International Organization for Standardization, Geneva, Switzerland). Available at https://www.iso.org/standard/20579.html. Accessed March 2, 2017.

[2] Standardization IOf (2002) ISO 10303-21:2002 - Industrial automation systems and integration - Product data representation and exchange - Part 21: Implementation methods: Clear text encoding of the exchange structure (International Organization for Standardization, Geneva, Switzerland). Available at https://www.iso.org/standard/33713.html. Accessed March 2, 2017.

[3] LOTAR - Long Term Archiving and Retrieval. Available at http://www.lotar-international.org/. Accessed March 2, 2017.

[4] ASD Strategic Standardization Group - Long Term Archiving and Retrieval - LOTAR. Available at http://www.asd-ssg.org/lotar. Accessed March 2, 2017.

[5] Boy J , Rosche P (CAx Implementor Forum. Available at http://www.cax-if.org/. Accessed March 2, 2017.

[6] Adachi Y (2013) IFCsvr ActiveX Component. Available at https://groups.yahoo.com/neo/groups/ifcsvr-users/info. Accessed March 2, 2017.

[7] Hardwick M (2017) STEPtools. Available at http://www.steptools.com/. Accessed March 2, 2017.

[8] ASD Strategic Standardization Group (2014) Development of STEP AP242 Edition 2 - Managed Model Based 3D Engineering. Available at http://www.asd-ssg.org/step-ap242-ed2. Accessed March 2, 2017.

[9] ASD Strategic Standardization Group (2009) Development of a Convergent Modular STEP Application Protocol Based on AP 203 and AP 214: STEP AP 242 - Managed Model Based 3D Engineering. Available at http://www.ap242.org/. Accessed March 2, 2017.

[10] STEP AP242 Project. Available at http://www.ap242.org/. Accessed March 2, 2017.

[11] Lipman R , Lubell J (2015) Conformance checking of PMI representation in CAD model STEP data exchange files. ComputerAided Design 66:14-23. https://doi.org/10.1016/j.cad.2015.04.002

[12] Boy J , Rosche P (2014) Recommended Practices for Representation and Presentation of Product Manufacturing Information (PMI) (AP242). CAx Implementor Forum, Technial Report

About the author: Robert Lipman is a research engineer at NIST. He develops software and product data to support the exchange of information and development of standards for the smart manufacturing digital thread. The National Institute of Standards and Technology is an agency of the U.S. Department of Commerce. 